\title{
Variation of Total Ozone during 24 August 2005 Magnetic Storm: A Case Study
}

\author{
Gustavo A. Mansilla ${ }^{1,2}$ \\ ${ }^{1}$ Departamento de Física, Facultad de Ciencias Exactas y Tecnología, Universidad Nacional de Tucumán, \\ San Miguel de Tucumán, Argentina \\ ${ }^{2}$ Consejo Nacional de Investigaciones Científicas y Técnicas, Buenos Aires, Argentina \\ Email: gmansilla@herrera.unt.edu.ar
}

Received June 11, 2013; revised July 13, 2013; accepted July 21, 2013

Copyright (C) 2013 Gustavo A. Mansilla. This is an open access article distributed under the Creative Commons Attribution License, which permits unrestricted use, distribution, and reproduction in any medium, provided the original work is properly cited.

\begin{abstract}
This paper presents the longitudinal distribution of total ozone along several latitudinal circles from both hemispheres during a strong geomagnetic storm that occurred on 24 August 2005 after a solar proton event (the maximum flux of protons with energy $>10 \mathrm{MeV}$ was $1.70 \times 10^{7}$ protons $\mathrm{cm}^{-2} \cdot \mathrm{day}^{-1} \cdot \mathrm{sr}^{-1}$ on 23 August). For that, we use average daily values of total ozone observations (=column ozone amount) in Dobson units for the period 18-25 August 2005 (obtained from the Total Ozone Mapping Spectrometer, TOMS). The considered storm occurred after a relatively quiet geomagnetic period and it is not superposed by another perturbation, which permit us to identify clearly the effects of the geomagnetic storm on total ozone. The results show statistically significant decreases in ozone along the latitudinal circles $70^{\circ} \mathrm{N}$ and $70^{\circ} \mathrm{S}$ (summer and winter), no statistically significant effects at middle latitudes $\left(40^{\circ} \mathrm{S}\right.$ ) and sparse statistically significant increases at low latitudes $\left(20^{\circ} \mathrm{S}\right)$. The role of some mechanisms to explain the features observed is considered.
\end{abstract}

Keywords: Solar Proton Event; Geomagnetic Storm; Ozone; Hemispheres

\section{Introduction}

Solar Proton Events (SPEs) occur when protons with very high energy are emitted by the Sun during solar flares or coronal mass ejections (CME), sometimes toward the Earth. High energy solar protons can penetrate the Earth's magnetic field near the poles. These protons penetrate into the atmosphere, typically to the 40 to 80 $\mathrm{km}$ height. Only 12 - 15 events per solar cycle can be recorded at the ground level [1]. In this way, they provide a direct connection between the Sun and the Earth's middle atmosphere [2]. Geomagnetic storms (temporary disturbances of the Earth's magnetic field) can be expected during solar flares and CMEs but not because of the increase of charged particles into the Earth's magnetosphere. They can occur when the interplanetary magnetic field (IMF) is southward and the solar wind crosses the Earth for long duration of time or in shorter more energetic bursts (flares/CMEs). When the IMF is southward, a magnetic reconnection of the dayside magnetopause is produced, rapidly injecting magnetic and particle energy into the Earth's magnetosphere.

Geomagnetic storms cause large disturbances in the upper atmosphere (ionosphere and thermosphere) including also the middle atmosphere and the troposphere $[3,4]$. Solar energetic particles which reach middle atmosphere cause ionization of air molecules. As the ionized molecules recombine, they produce nitrogen and hydrogen oxides which can affect ozone through odd nitrogen $\mathrm{NO}_{\mathrm{y}}$ and odd hydrogen $\mathrm{HO}_{\mathrm{x}}$ catalytic reactions (see e.g., [5] for details). Decreases of ozone in the middle atmosphere after large solar proton events have been predicted by atmospheric models (e.g., Whole Atmosphere Community Climate Model WACCM3), and also observed by satellite measurements [6-8]. The stratospheric ozone effects were caused by the odd nitrogen. Very large $\mathrm{NO}_{\mathrm{y}}$ enhancements lasted for months in the middle and lower stratosphere after some largest SPEs. Using a two-dimensional chemistry and transport atmosphere model, [9] compute the effects of gigantic SPEs in the stratosphere. They obtained upper stratospheric ozone depletions $>$ $10 \%$ to last for a few months after the SPEs. Moreover, during the October-November 2003 series of solar proton events, ozone depletion varying from $20 \%$ at $40 \mathrm{~km}$ altitude to more than $95 \%$ at $78 \mathrm{~km}$ was found [10].

Some studies show that during intense geomagnetic 
storms the total ozone presents a pattern which is statistically significant at the northern higher middle latitudes only under very limited conditions [11]: in winter and under the high solar activity and the East phase of the QBO conditions. At around $50^{\circ} \mathrm{N}$ latitudinal circle, but not around $40^{\circ} \mathrm{N}$ and $60^{\circ} \mathrm{N}$, the effect appears to be basically re-distribution of ozone (in the North AtlanticEuropean it means an increase of the total ozone), neither its loss, nor its production.

This short paper shows the short-term latitudinal disturbances in the total ozone content as consequence of an isolated geomagnetic storm occurred during the descending phase of solar cycle 23 (solar flux on storm day: 100.7). Since this storm came after a relatively quiet solar/magnetic period and it is not superposed upon by another perturbation, it is reasonable to assume that the variations on total ozone during the considered storm period are caused by the geomagnetic storm. In fact, the selected geomagnetic storm was characterized by an SSC (storm sudden commencement), which was preceded by quiet days and without the arrival of a new solar rapid flow during its phase of recovery, that is, a new storm is not superimposed. Moreover, with the results obtained here we can check the pattern of total ozone variation during geomagnetic storm obtained by [11].

Case studies which consider several latitudes from both hemispheres are rare but they are important for a view of global space weather and also to know and/or check the role of possible physical mechanisms. In addition, the ozone response to geomagnetic storms has not been given adequate attention over Southern latitudes [12].

We will first describe the datasets used for quantifying the total ozone response to the geomagnetic storm. After that, present our observations. Finally, a discussion and the conclusion are given in Section 4.

\section{Data}

The database used in this study consists of average daily values of total ozone observations (=column ozone amount) in Dobson units for the period 18-25 August 2005, which were obtained from the Total Ozone Mapping Spectrometer (TOMS) (http://jwocky.gsfc.nasa.gov/ ozone/ozone.html). We considered the measurements obtained each $10^{\circ}$ of geographic longitude, between $-180^{\circ}$ and $+180^{\circ}$ (37 observations) at different latitudinal circles of the Norhtern Hemisphere $(\mathrm{NH})$ and the Southern Hemisphere (SH): $20^{\circ}, 40^{\circ}, 60^{\circ}$ and $70^{\circ}$.

The Earth Probe EP-TOMS instrument measures backscattered ultraviolet radiance from Earth at wavelength bands centered at 308.6, 313.5, 317.5, 322.3331 .2 and $360.4 \mathrm{~nm}$. One significant difference in the EP-TOMS series from the previous Nimbus-7 and Meteor 3 TOMS is a change is the wavelength selection for the 6 channels of the three new instruments. Four of the nominal band center wavelengths remain the same on all TOMS. Channels measuring at $340 \mathrm{~nm}$ and $380 \mathrm{~nm}$ have been eliminated in favor of $309 \mathrm{~nm}$ and $322 \mathrm{~nm}$ on the new TOMS. Ozone retrieval at $309 \mathrm{~nm}$ is advantageous because of the relative insensitivity to calibration errors, though retrievals are limited to equatorial regions. Ozone retrievals at high latitudes are improved because $322 \mathrm{~nm}$ is a better choice for the optical paths encountered there [13]. Total column ozone is inferred from the differential absorption of scattered sunlight in the ultraviolet using the ratio of two wavelengths, $312 \mathrm{~nm}$ and $331 \mathrm{~nm}$ for instance, where one wavelength is strongly absorbed by ozone while the other is weakly absorbed. TOMS is subject to errors and random uncertainties. Some of these errors come from the instrument and others from environmental phenomenon. Aside from some known problems at specific times and locations, accuracy is believed to be within $3 \%-4 \%$ of actual ozone levels.

The magnetic activity as represented by the geomagnetic index Dst. The hourly values of Dst were obtained from the world Data Center at the University of Kyoto database (http://swdc.kugi.kyoto-u.ac.jp/dstdir).

\section{Results}

In August 2005, the Sun released a solar flare (M5/1N) associated with a CME (Halo/22 1730). Consequently the flux of particles toward the Earth's atmosphere was greatly enhanced. A solar proton event began on $22 \mathrm{Au}-$ gust 2005 at 2040 UT, reaching a maximum on the following day at 1045 UT. Figure 1 shows the daily measurements of the proton fluence taken by the GOES-11 satellite during August 2005 (http://www.swpc.noaa.gov/ ftpmenu/warehouse/2005.html. For the more important proton event occurred during August 2005 it can be seen that the protons with different energies are increased by several orders of magnitude. The flux of the protons with energy $>10 \mathrm{MeV}$ was about $1.60 \times 10^{4}$ protons $\mathrm{cm}^{-2}$. day $^{-1} \cdot \mathrm{sr}^{-1}$ prior to the solar flare, and reached a maximum of $1.70 \times 10^{7}$ protons $\mathrm{cm}^{-2} \cdot \mathrm{day}^{-1} \cdot \mathrm{sr}^{-1}$ on 23 August.

We focused the analysis on the geomagnetic storm that took place two days after SPE. Figure 2 shows the geomagnetic index Dst for August 2005. It can be clearly seen the only intense geomagnetic storm occurred that month: the magnetic storm started on 24 August $\left(\sum \mathrm{k}_{\mathrm{p}}=\right.$ $46 ; A_{p}=102$ ) with a sudden commencement at 0613 UT. An abrupt decrease is observed at about 11 - 12 UT that day when Dst reached its minimum of $-216 \mathrm{nT}$ after which started a relatively rapid recovery.

We selected ten magnetically quiet days of the month of the storm to obtain an average pre-storm quiet level of total ozone and calculate the average value and $\sigma$ separately for each latitudinal circle. The storm effect in the 


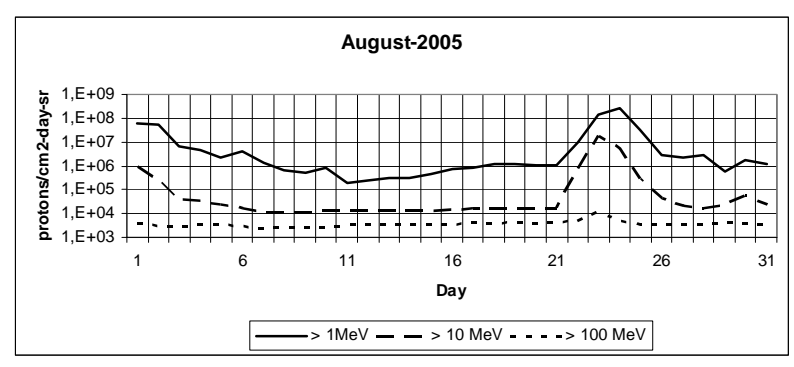

Figure 1. Daily values of proton fluence (protons $/ \mathrm{cm}^{2} / \mathrm{day} /$ sr) for August 2005, measured by GOES-11 satellite. Three curves indicate protons with energies above 1, 10 and 100 MeV.

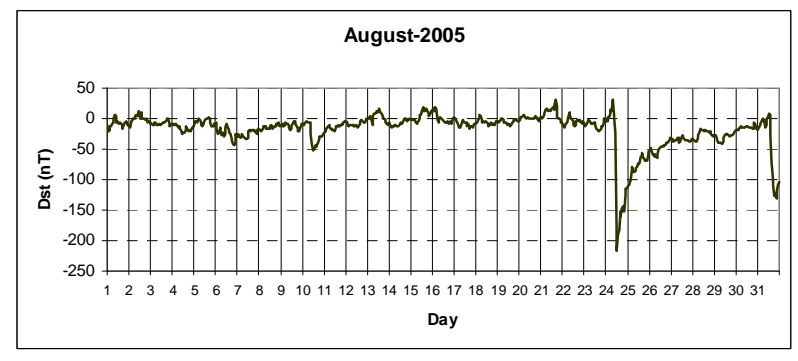

Figure 2. Hourly variation of the geomagnetic index Dst for August 2005. It can be observed the only intense storm occurred that month.

total ozone may be considered as significant if the deviation in individual storm days exceeds $2 \sigma$. This is the usual criterion normally used to demonstrate the existence of a storm effect in variations of any geophysical parameter [12]. Some cases with statistically significant deviation $(>2 \sigma)$ and no statistically significant deviation are shown in this paper.

Figures 3 and $\mathbf{4}$ display the longitudinal variation of the total ozone at the latitudes $70^{\circ} \mathrm{N}$ and $70^{\circ} \mathrm{S}$ (summer and winter hemispheres, respectively) for the storm period 22-25 August together with $\pm 2 \sigma$ (thin curves). It can be seen that the behavior of total ozone differs substantially in the individual days and does not reveal any persistent pattern. Statistically significant decreases in total ozone are observed in the $30^{\circ}-120^{\circ}$ longitude sector (Northern Europe) on the storm day (24 August), and in the longitude range $-70^{\circ}$ to $-30^{\circ}$ and $-150^{\circ}$ to $-120^{\circ}$ in the Southern Hemisphere on 23 and 24 August. It can be seen that individual days differ substantially and do not reveal any persistent pattern.

Figure 5 shows the variation in total ozone at $60^{\circ} \mathrm{S}$ (winter). One can observe that the variations of total ozone in the individual days show a similar trend. The higher values of total ozone are observed in the east sector (about $60^{\circ}-120^{\circ}$ longitude). Statistically significant increases in total ozone are observed at longitudes between $-120^{\circ}$ and $-60^{\circ}$ and between $+60^{\circ}$ and $+120^{\circ}$ on 24-25 August, and statistically significant decreases at higher longitudes $\left(\sim 150^{\circ}-180^{\circ}\right)$ in the west and the east

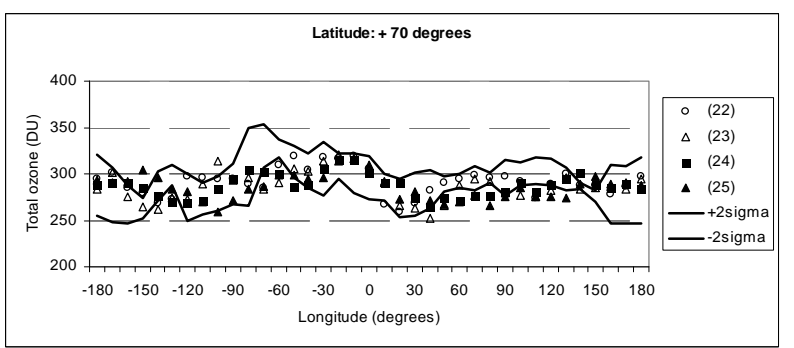

Figure 3. Longitudinal variation of total ozone on 22-25 August 2005 along the latitudinal circle $70^{\circ} \mathrm{N}$ for the geomagnetic storm occurred on 24 August. Thin curves indicate $+/-2 \sigma$ uncertainty.

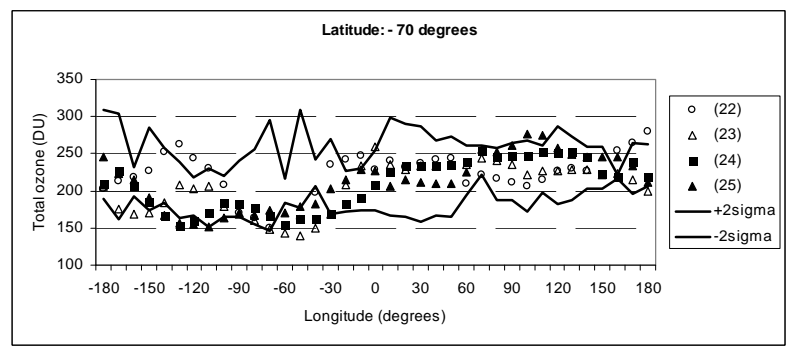

Figure 4. Same as Figure 3 but for the latitudinal circle $\mathbf{7 0}^{\circ} \mathrm{S}$.

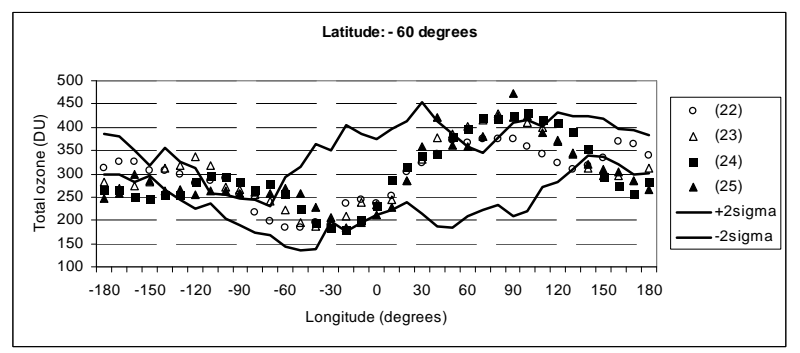

Figure 5. Same as Figure 3 but for the latitudinal circle $60^{\circ} \mathrm{S}$.

sectors. The total ozone at $60^{\circ} \mathrm{N}$ in the summer hemisphere (not shown here) reveals similar behavior that the winter hemisphere.

Figure 6 shows the behavior in total ozone at the latitude $40^{\circ} \mathrm{S}$. As at higher latitudes, the total ozone values at mid latitudes differ each day and they do not reveal any regular pattern. A statistically significant effect of the intense geomagnetic storm in ozone is observed only between $-120^{\circ}$ and $-100^{\circ}$ of the Southern Hemisphere. Similar result (not shown here) is observed for $40^{\circ} \mathrm{N}$.

Figure 7 presents the variation in total ozone along the latitudinal circle $20^{\circ} \mathrm{S}$ (winter). Statistically significant increases can be observed between $-60^{\circ}$ and $-150^{\circ}$ on 24-25 August. The rest of the longitudinal sectors do not present any evident effect of the geomagnetic storm on total ozone.

In order to determine a possible longitudinal re-distribution of total ozone during a geomagnetic storm, we calculated "the mean zonal total ozone" $\mathrm{TO}_{3}$-zonal. This 
parameter was defined as follows: the quotient between the difference of the average of the measurements taken each 10 degrees during the storm days in each longitudinal circle and the average pre-storm values above mentioned, and the average pre-storm values (in percentage). Figures 8 and 9 show the results for the summer and

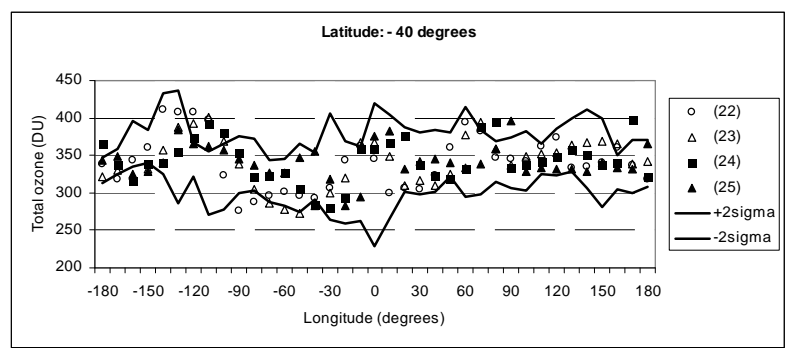

Figure 6. Same as Figure 3 but for the latitudinal circle $40^{\circ} \mathrm{S}$.

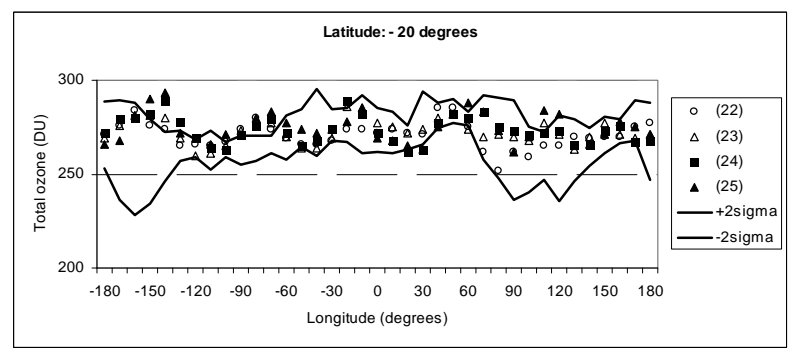

Figure 7. Same as Figure 3 but for the latitudinal circle $20^{\circ} \mathrm{S}$.

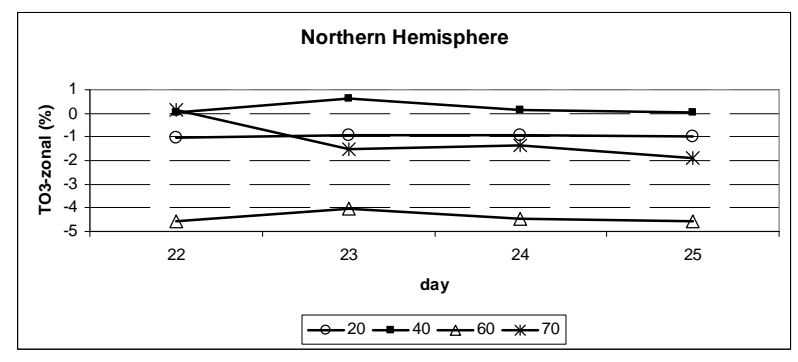

Figure 8. Relative variation of the zonal mean total ozone along several latitudinal circles $\left(20^{\circ}, 40^{\circ}, 60^{\circ}\right.$ and $\left.70^{\circ}\right)$ for the Northern Hemisphere during the storm period 22-25 August 2005.

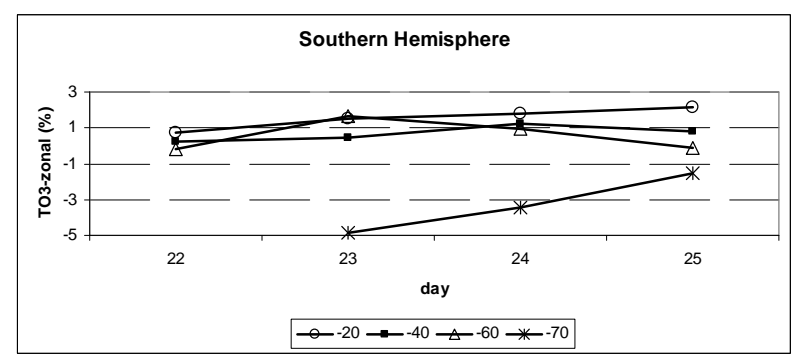

Figure 9. Same as Figure 8 but for the Southern Hemisphere. winter hemispheres respectively. At the Northern Hemisphere (summer), the larger decrease is produced at $60^{\circ} \mathrm{N}$ $(<5 \%)$; at higher latitudes $\left(70^{\circ} \mathrm{N}\right)$ the decrease is lower in association with statistically significant decreases, while at middle and low latitudes no substantial change is observed $(<1 \%)$. At the Southern Hemisphere (winter) the larger decrease occurs in the high latitude region $(<5 \%)$ also in association with statistically significant decreases, whereas at low latitude there is a small increase. The magnitude of the changes in both hemispheres seems to indicate that at $60^{\circ} \mathrm{N}$ in the summer hemisphere and at higher latitudes from the winter hemisphere there is a decrease in ozone, while at the other latitudes would occur zonal re-distribution in ozone.

\section{Discussion and Conclusions}

This paper reports the longitudinal variation of the total ozone measured along different latitudinal circles at the Northern and Southern Hemispheres during the isolated geomagnetic storm occurred on 24 August 2005.

The main observational results can be roughly summarized as follows:

- Along the latitudinal circles $70^{\circ} \mathrm{N}$ and $70^{\circ} \mathrm{S}$ statistically significant decreases in total ozone are observed in the Northern Europe $\left(30^{\circ}-120^{\circ}\right.$ longitude sector) on the storm day, and in the longitude range $-70^{\circ}$ to $-30^{\circ}$ and $-150^{\circ}$ to $-120^{\circ}$ in the Southern Hemisphere.

- Along the latitudinal circle $60^{\circ} \mathrm{S}$ statistically significant increases in total ozone are produced at longitudes between $-120^{\circ}$ and $-60^{\circ}$ and between $60^{\circ}$ and $120^{\circ}$ and decreases at higher longitudes in the west and east sectors on 24 August.

- At mid latitudes $\left(40^{\circ} \mathrm{S}\right)$ no statistically significant effect of geomagnetic storm in ozone is observed, while at low latitudes $\left(20^{\circ} \mathrm{S}\right)$ they are sparse.

- In general, the longitudinal distribution in total ozone shows small loss in both hemispheres during SPE event on 22 August 2005. At the $\mathrm{NH}$ the maximum loss is observed around the $60^{\circ} \mathrm{N}$ latitudinal circle $(\sim 5 \%)$; around the longitudinal circles corresponding at $40^{\circ} \mathrm{N}$ and $70^{\circ}$ the loss is of the order $1 \%-2 \%$. At the $\mathrm{SH}$ no significant production in total ozone is observed at around the $20^{\circ}$ longitudinal circle $(\sim 1 \%$ $2 \%$ ), almost no changes at $40^{\circ} \mathrm{S}$ and $60^{\circ} \mathrm{S}$, and at $70^{\circ}$ loss in the total ozone $(\sim 5 \%)$ the day of the greater proton fluence. These results seem to suggest a redistri- bution of the total ozone only in some latitudinal cir- cles, where the relative deviation of the "zonal total ozone" is lower than $1 \%-2 \%$. It might owe to changes in the stratospheric storm-time circulation which could produce redistribution of ozone along longitudinal circles.

The results obtained here suggest that total ozone is affected by geomagnetic disturbances. According to [11], 
the Northern Hemisphere is not under all the favourable conditions for a significant ozone response during the considered event because $\mathrm{NH}$ is in the summer season.

Analyzing 5 strong geomagnetic storms occurred in July-August for the period 1982-1991, [12] found that contrary to the Northern Hemisphere, detectable effects of geomagnetic storms on total ozone do not occur at the Southern Hemisphere higher middle latitudes. On the contrary, we found longitudinal variations at $60^{\circ}-70^{\circ}$ in winter in the Southern Hemisphere.

Some total ozone column depletions are observed near the south boundary of the Atlantic South magnetic anomaly and close to the boreal geomagnetic pole which suggests that geomagnetic field longitude seems to play an important role in ozone variation. The ozone change in the South Atlantic anomaly agrees with [14], who observed mesospheric ozone depletion in that region.

There is an evident depletion of total ozone $(\sim 5 \%)$ during the strong geomagnetic storm in the $60^{\circ} \mathrm{N}$ and $70^{\circ} \mathrm{S}$ longitudinal circles. During both quiet and disturbed conditions the Antarctic polar vortex creates ozone depletion. A speculative and no verifiable explanation is that the polar vortex plays a significant role in the loss of ozone at high latitudes of the winter hemisphere during the storm. However, satellite observations taken during polar winter in the Antarctic indicate $\mathrm{NO}_{\mathrm{x}}$ enhancements, which occur in good correlation with levels of enhanced high-energy particle precipitation (associated with SPEs) and/or geomagnetic activity (e.g., $[6,15])$.

A possible explanation of the depletion of ozone in the Northern Hemisphere could be related with changes in $\mathrm{HO}_{\mathrm{x}}$ and $\mathrm{NO}_{\mathrm{x}}$. In fact, upper stratospheric enhancements in $\mathrm{NO}_{\mathrm{x}}$ were measured at northern high latitudes during storms [16,17]. Measurements from the UARS HALOE and NOAA 14 SBUV/2 instruments indicate short-term ( day) middle mesospheric ozone decreases for over $70 \%$ caused by short-lived $\mathrm{HO}_{\mathrm{x}}$ during a SPE with a longer-term (several days) upper stratospheric ozone depletion of up to $9 \%$ caused by longer-lived $\mathrm{NO}_{\mathrm{x}}$.

Unfortunately no available study about the changes of $\mathrm{NO}_{\mathrm{x}}$ in the middle atmosphere in the case of this SPE has been found, which prevents the confirmation of that assumption.

The ozone depletion observed in summer differs from the results obtained by other authors who found that significant effects of geomagnetic storms on total ozone (redistribution in ozone, not ozone production or loss) have been observed only in winter and for strong storms $\left(A_{p}>40\right)$ and only under specific conditions $[11,18,19]$. Because each storm has its individual characteristics we believe that actual patterns of response are not consistent yet because deviations from the model pattern are observed. For that reason more case studies are necessary to obtain some common/consistent storm-time features.
In summary, we analyzed the short-term response of the total ozone content to an isolated geomagnetic storm along several latitudinal circles from both hemispheres (summer and winter). The total ozone content exhibits redistribution at middle and low latitudes $\left(20^{\circ}-40^{\circ}\right)$ in both hemispheres and decreases at higher latitudes (in winter and summer) the days of great proton fluence. This result is a new one and can be considered as the main contribution of this paper to current community knowledge on total ozone storm effects because it differs from obtained by other authors [12]. It is clear that the present results may be significant and could have important implications for the study of the behavior of the atmosphere during geomagnetic storms, contain little statistical information. Because of the discrepancy of the results for the different authors, it is evident that it is necessary to perform further analysis of satellite measurements in order to infer a statistics about the standards of behavior of the total ozone during disturbed periods.

\section{REFERENCES}

[1] G. A. Basilevskaya, "Solar Cosmic Rays near Earth Space and the Atmosphere," Advances in Space Research, Vol. 35, No. 3, 2005, pp. 458-464.

http://dx.doi.org/10.1016/j.asr.2004.11.019

[2] A. Seppälä, P. T. Verronen, E. Kyrola, S. Hassinen, L. Backman, A. Hauchecorne, J. L. Bertaux and D. Fussen, "Solar Proton Events of October-November 2003: Ozone Depletion in the Northern Hemisphere Polar Winter as Seen by GOMOS/Envisat," Geophysical Research Letters, Vol. 31, No. 19, 2004, Article ID: L19107,.

http://dx.doi.org/10.1029/2004GL021042

[3] J. Lastovicka, "Effects of Geomagnetic Storms in the Lower Ionosphere, Middle Atmosphere and Troposphere," Journal of Atmospheric and Solar Terrestrial Physics, Vol. 58, No. 7, 1996, pp. 831-843. http://dx.doi.org/10.1016/0021-9169(95)00106-9

[4] G. A. Mansilla, "Response of the Lower Atmosphere to Intense Geomagnetic Storms," Advances in Space Research, Vol. 48, No. 5, 2011, pp. 806-810.

[5] G. Brasseur and S. Solomon, "Aeronomy of the Middle Atmosphere-Chemistry and Physics of the Stratosphere and Mesosphere," 3rd Edition, Springer, Berlin, 2005.

[6] A. Seppälä, P. T. Verronen, M. A. Clilverd, C. E. Randall, J. Tamminen, V. Sofieva, L. Backman and E. Kyrölä, "Arctic and Antarctic Polar Winter $\mathrm{NO}_{\mathrm{x}}$ and Energetic Particle Precipitation in 2002-2006," Geophysical Research Letters, Vol. 34, No. 12, 2007, Article ID: L12810. http://dx.doi.org/10.1029/2007GL029733

[7] E. Turunen, P. T. Verronen, A. Sepällä, C. J. Rodger, M. A. Cliverd, J. Tamminen, C. F. Enell and T. Ulich, "Impact of Different Energies of Precipitating Particles on $\mathrm{NO}_{\mathrm{x}}$ Generation in the Middle and Upper Atmosphere during Geomagnetic Storms," Journal of Atmospheric and Solar-Terrestrial Physics, Vol. 71, No. 10-11, 2008, pp. 1176-1189. 
http://dx.doi.org/10.1016/i.jastp.2008.07.005

[8] C. H. Jackman, D. R. Marsh, F. M. Vitt, R. R. Garcia, C. E. Randall, E. L. Fleming and S. M. Frith, "Long-Term Middle Atmospheric Influence of Very Large Solar Proton Events," Journal of Geophysical Research, Vol. 114, No. D11, 2009, pp. 1984-2012. http://dx.doi.org/10.1029/2008JD011415

[9] C. H. Jackman, E. L. Fleming and F. M. Vitt, "Influence of Extremely Large Proton Events in a Changing Stratosphere," Journal of Geophysical Research, Vol. 105, No. D9, 2000, pp. 11659-11670. http://dx.doi.org/10.1029/2000JD900010

[10] P. T. Verronen, A. Seppala, M. A. Cliverd, C. J. Rodger, E. Kyrola, C. Enell, T. Ulich and E. Turunen, "Diurnal Variation of Ozone Depletion during the October-November Solar Proton Events," Journal of Geophysical Research, Vol. 110, No. A9, 2005, pp. 1978-2012. http://dx.doi.org/10.1029/2004JA010932

[11] J. Lastovicka and P. Krizan, "Geomagnetic Storms, Forbush Decreases of Cosmic Rays and Total Ozone at Northern Higher Middle Latitudes," Journal of Atmospheric and Solar-Terrestrial Physics, Vol. 67, No. 1-2, 2005, pp. 119-124. http://dx.doi.org/10.1016/j.jastp.2004.07.021

[12] J. Lastovicka and P. Krizan, "Impact of Strong Geomagnetic Storms on Total Ozone at Southern Higher Middle Latitudes," Studia Geophysica et Geodaetica, Vol. 53, No. 1, 2009, pp. 151-156. http://dx.doi.org/10.1007/s11200-009-0009-7

[13] R. D. McPeters, P. K. Bhartia, A. J. Krueger, J. R. Herman, C. G. Wellemeyer, c: J. Seftor, G. Jaross, O. Torres, L. Moy, G. Labow, W. Byerly, S. L. Taylor, T. Swissler and R. P. Cebula, "Earth Probe Total Ozone Mapping Spectrometer (TOMS) Data Products User's Guide,"
NASA Technical Publication 206895, Goddard Space Flight Center Greenbelt, 1998.

[14] O. Pinto, V. W. Kirchhoff and W. D. Gonzales, "Mesospheric Ozone Depletion Due to Energetic Electron Precipitation at the South Atlantic Magnetic Anomaly," Annales Geophysicae, Vol. 8, No. 5, 1990, pp. 365-368.

[15] C. H. Jackman, M. T. DeLand, G. J. Labow, E. L. Fleming, D. K. Weisenstein, M. K. W. Ko, M. Sinnhuber and J. M. Russell, "Neutral Atmospheric Influences of the Solar Proton Events in October-November 2003," Journal of Geophysical Research, Vol. 110, No. A9, 2005, Article ID: A09S27. http://dx.doi.org/10.1029/2004JA010888

[16] C. H. Jackman, R. D. McPeters, G. J. Labow, E. L. Fleming, C. J. Praderas and J. M. Russell, "Northern Hemisphere Atmospheric Effects Due to the July 2000 Solar Proton Event," Geophysical Research Letters, Vol. 28, No. 15, 2001, pp. 2883-2886. http://dx.doi.org/10.1029/2001GL013221

[17] C. E. Randall, V. L. Harvey, G. L. Manney, Y. Orsolini, M. Codrescu, C. Sioris, S. Brohede, C. S. Haley, L. L. Gordley, J. M. Zawodny and J. M. Russell, "Stratospheric Effects of Energetic Particle Precipitation in 2003-2004," Geophysical Research Letters, Vol. 32, No. 5, 2005, Article ID: L05802. http://dx.doi.org/10.1029/2004GL022003

[18] P. Mlch, "Total Ozone Response to Major Geomagnetic Storms during Non-Winter Period," Studia Geophysica et Geodaetica, Vol. 38, No. 4, 1994, pp. 423-429. http://dx.doi.org/10.1007/BF02296172

[19] J. Lastovicka and P. Mlch, "Is Ozone Affected by Geomagnetic Storms?" Advances in Space Research, Vol. 24, No. 5, 1999, pp. 631-640. http://dx.doi.org/10.1016/S0273-1177(99)80136-7 